\title{
Perencanaan Strategis Sistem Informasi / Teknologi Informasi Di Balai Riset Dan Standardisasi Industri Surabaya
}

\author{
Information System / Information Technology Strategic Planning \\ In Balai Riset Dan Standardisasi Industri Surabaya
}

\author{
Purnomo Yogi Dewantara \\ Institut Teknologi 10 Nopember \\ Fakultas Bisnis dan Manajemen Teknologi \\ Surabaya, Indonesia \\ purnomoyogi@hotmail.com
}

\author{
Febriliyan Samopa \\ Institut Teknologi 10 Nopember \\ Fakultas Teknologi Informasi \\ Surabaya, Indonesia
}

\begin{abstract}
Abstrak - Baristand Industri Surabaya memiliki aset - aset teknologi informasi (TI) untuk membantu kegiatan - kegiatan bisnisnya. Adanya tuntutan - tuntutan baru menyebabkan terjadinya perubahan paradigma pengelolaan TI, dari sebagai pembantu kegiatan operasional menjadi pendukung keberhasilan strategi. Cara pengelolaan TI yang sedang berjalan dirasa tidak lagi mencukupi, karena belum ada pedoman untuk memastikan agar TI berfungsi optimal sebagai pendukung strategi.

Solusi yang digunakan pada penelitian ini untuk permasalahan tersebut, adalah penyusunan rencana strategis Sistem Informasi dan Teknologi Informasi (SI/TI) dengan metode Ward dan Peppard, yang merupakan metode perencanaan yang bertujuan untuk menghasilkan strategi SI/TI yang selaras dengan strategi bisnis. Tahapan pertama implementasi metode tersebut dalam penelitian ini adalah analisis kondisi saat ini, baik pada organisasi secara keseluruhan maupun pada aspek SI/TI, untuk mendapatkan gambaran posisi strategis organisasi . Tahapan berikutnya adalah analisis kebutuhan SI/TI masa mendatang, untuk mengetahui kesenjangan SI/TI di organisasi. Tahapan terakhir adalah menyusun usulan langkah - langkah strategis SI/TI.

Implementasi metode Ward dan Peppard di penelitian ini mampu mengidentifikasi kebutuhan SI/TI Baristand Industri Surabaya, kecuali satu kebutuhan yang muncul dari tuntutan pemerintah dan masyarakat yang baru muncul. Selain itu rekomendasi yang dihasilkan juga harus disesuaikan melalui proses prioritisasi karena berbagai keterbatasan yang dihadapi. Penyertaan langkah prioritisasi dengan metode Ward dan Peppard merupakan pendekatan yang belum umum digunakan. Diharapkan penelitian ini dapat membantu instansi publik lainnya yang mengalami hambatan serupa dalam menyusun strategi SI/TI.

Kata Kunci---Perencanaan Strategis SI/TI, Metode Ward dan Peppard, Baristand Industri Surabaya, Portfolio Aplikasi
\end{abstract}

\begin{abstract}
Baristand Industri Surabaya is a work unit of The Ministry of Industy. Baristand Industri Surabaya own information technology (IT) asset for assisting it's business activities. The existence of new demands lead to paradigm change in IT management, from assissting operational activities to supporting strategic success. The current method of IT management is considered to be no longer adequate, since there is not yet a guideline for making sure that IT functions optimally as strategic support.
\end{abstract}

The solution used in this research for those problems is formulating an Information System and Information Technology (IS/IT) strategic plan, using Ward and Peppard Method, which is an IS/IT strategic planning method which aim to produce an IS/IT strategy that is aligned with business strategy. In this research, the first stage for implementing Ward and Peppard method is analyzing current situation, both for the entire organization and for IS/IT management, in order to get a picture of the organization's strategic position. The next stage is analyzing future IS/IT needs, to identify IS/IT gaps in the organization. The final stage is formulating IS/IT strategic steps.

The impelementation of Ward and Peppard method in this research was successful in identifying IS/IT needs of Baristand Industri Surabaya, except for one that arose recently from government and public demand. Furthermore the produced recommendation had to adjusted using prioritization process due to various constraints that are being faced. The inclusion of prioritization steps with Ward and Peppard method is not yet common. It is hoped that that this research can assist other public institutions that face similar constraints in formulating there is/IT strategy.

Keywords---IS/IT Strategic Planning, Ward and Peppard Method, Baristand Industri Surabaya, Application Portfolio 


\section{PENDAHULUAN}

Balai Riset dan Standardisasi (Baristand) Industri Surabaya merupakan salah satu satu satuan kerja di lingkungan Kementerian Perindustrian. Baristand Industri Surabaya merupakan satu dari 23 balai riset yang dikelola oleh Badan Pengembangan dan Penelitan Industri (BPPI). Kegiatan bisnis dan pelayanan yang dilaksanakan di Baristand Industri Surabaya secara umum dibagi menjadi tiga. Kegiatan pertama yaitu penelitian dan pengembangan. Kegiatan kedua yaitu pengujian dan sertifikasi bahan, alat dan produk. Kegiatan ketiga yaitu pengembangan SDM dalam bentuk bimbingan, konsultasi dan pelatihan. Pelayanan Baristand utamanya dipasarkan, tetapi tidak terbatas, kepada sektor Industri di Jawa Timur atau industri perangkat elektronik rumah tangga nasional.

Segala kegiatan Baristand Industri Surabaya dilaksanakan dan dikelola oleh empat seksi dan satu sub bagian yaitu :

1). Seksi Standardisasi dan Sertifikasi

2). Seksi Pengembangan Jasa Teknis

3). Seksi Teknologi Industri

4). Seksi Program dan Pengembangan Kompetensi

5). Sub Bagian Tata Usaha

Selain itu Baristand Industri Surabaya dalam merencanakan kegiatan - kegiatnnya merujuk pada suatu rencana strategis (Renstra). Renstra merupakan rincian strategi bisnis dari Baristand Industri Surabaya yang diperbarui setiap lima tahun. Renstra berisi tujuan bisnis yang harus dicapai dan program - program apa saja yang harus terlaksana.

Untuk mendukung kegiatan - kegiatan pelayanan yang telah disebutkan, selain memiliki fasilitas seperti laboratorium, loket dan kantor, Baristand Industri Surabaya memiliki berbagai aset - aset Teknologi Informasi (TI). Pengelolaan TI menjadi tanggungjawab Seksi Pengembangan Jasa Teknis (PJT).

Seksi PJT melaksanakan pengelolaan TI dengan membentuk tim pengelola teknologi informasi setiap tahun. Tim pengelola TI melaksanakan program - program kerja yang telah dianggarkan, serta memberi saran untuk penyusunan program kerja tahun berikutnya. Tim TI juga dapat menerima saran dari pegawai - pegawai lain untuk saran progam kerja tahun mendatang. Setiap program kerja yang terlaksana dipertanggungjawabkan melalui laporan pertanggungjawaban tim pengelola TI. Laporan menyebutkan apakah program kerja telah dilaksanakan sesuai dengan spesifikasi serta dalam batasan waktu dan anggaran yang ditentukan.

Pada tahun 2015, timbul tuntutan - tuntuan baru atas Baristand Industri Surabaya. Kementerian Perindustrian pada umumnya dan Baristand Industri Surabaya pada khususnya, diperintahkan untuk melaksanakan program - program Reformasi Birokrasi. Menghadapi tuntutan - tuntutan tersebut, metode pengelolaan TI di Baristand Industri Surabaya dirasakan tidak lagi memadai. Ada perubahan paradigma yaitu TI tidak hanya pendukung kegiatan operasional melainkan juga mendukung tujuan bisnis Baristand Industri Surabaya.

Pengelolaan SI/TI di Baristand Industri Surabaya memiliki permasalahan - permasalahan berikut :

1. Belum terdapat dasar atau pedoman untuk mentukan kebutuhan - kebutuhan kapabilitas SI/TI di masa mendatang, sesuai dengan kondisi yang dihadapi oleh Baristand Industri Surabaya

2. Belum terdapat pedoman yang sistematis untuk perencanaan dan evaluasi program - program kerja TI dalam rangka mendukung pencapaian rencana strategis Baristand Industri Surabaya.

Perencanaan strategis SI/TI dapat membantu dalam mengatasi permasalahan - permasalahan tersebut. . Metode perencanaan strategis SI//TI dari Ward dan Peppard berfungsi untuk menghasilkan rencana strategis SI/TI yang menambah nilai bisnis dari organisasi, dengan kata lain terdapat keselarasan dengan strategi bisnis organisasi. Chan, Saberwhal dan Thatcher (2006) menyatakan bahwa keselarasan strategi SI dengan bisnis cenderung berkontribusi positif pada kinerja organisasi, walaupun dampaknya beragam dan tergantung pada tipe organisasi dan strategi bisnis yang dijalankan. Mereka juga menyatakan bahwa keuntungan dari keselarasan strategi bisnis dengan SI dapat semakin besar bila organisasi telah merencanakan proses berbagi pengetahuan (knowledge management) yang kuat.Selain itu metode ini juga mampu menghasilkan portfolio aplikasi - aplikasi yang harus diperoleh sehingga membantu keputusan investasi TI.

Terdapat dua tujuan dari penelitian ini. Keduanya adalah sebagai berikut :

1) Meneliti apakah metode Ward dan Peppard sesuai untuk diimplementasikan di Baristand Industri Surabaya untuk mengidentifikasi kebutuhan SI/TI dan memberikan basis bagi strategi SI/TI, yang sesuai dengan kondisi dan batasan yang dihadapi .

2) Meneliti kemampuan metode Ward dan Peppard untuk menghasilkan usulan - usulan strategis SI/TI yang mendukung pencapaian rencana strategis Baristand Industri Surabaya.

Di sisi lain, rencana strategis SI/TI harus fleksibel dan sesuai dengan lingkungan, kultur kerja dan kondisi organisasi. Kondisi lingkungan eksternal bisnis dapat berubah sewaktu waktu dan sulit diprediksi. Garg, Joubert dan Pellisier (2005), menyatakan bahwa SI tidak hanya mampu membantu mencapai keunggulan kompetitif tetapi juga membantu menilai lingkungan eksternal. Selain itu, . Tanriverdi, Rai dan Venkatraman (2010) menyimpulkan pada lingkungan bisnis 
yang cenderung cepat berubah, TI sebaiknya disusun secara semi-terstruktur, agar lebih fleksibel dalam menghadapi perubahan.

\section{BAHAN DAN METODE}

Penelitian ini telah dilakukan dalam enam tahap. Keenam tahap itu adalah tahap pendahuluan, tahap pengumpulan data dan informasi, tahap pemahaman situasi terkini, tahap penentuan kebutuhan untuk masa depan, tahap formulasi strategi dan terakhir penyusunan portfolio aplikasi. Ilustrasi skema ada pada gambar 1 berikut ini :

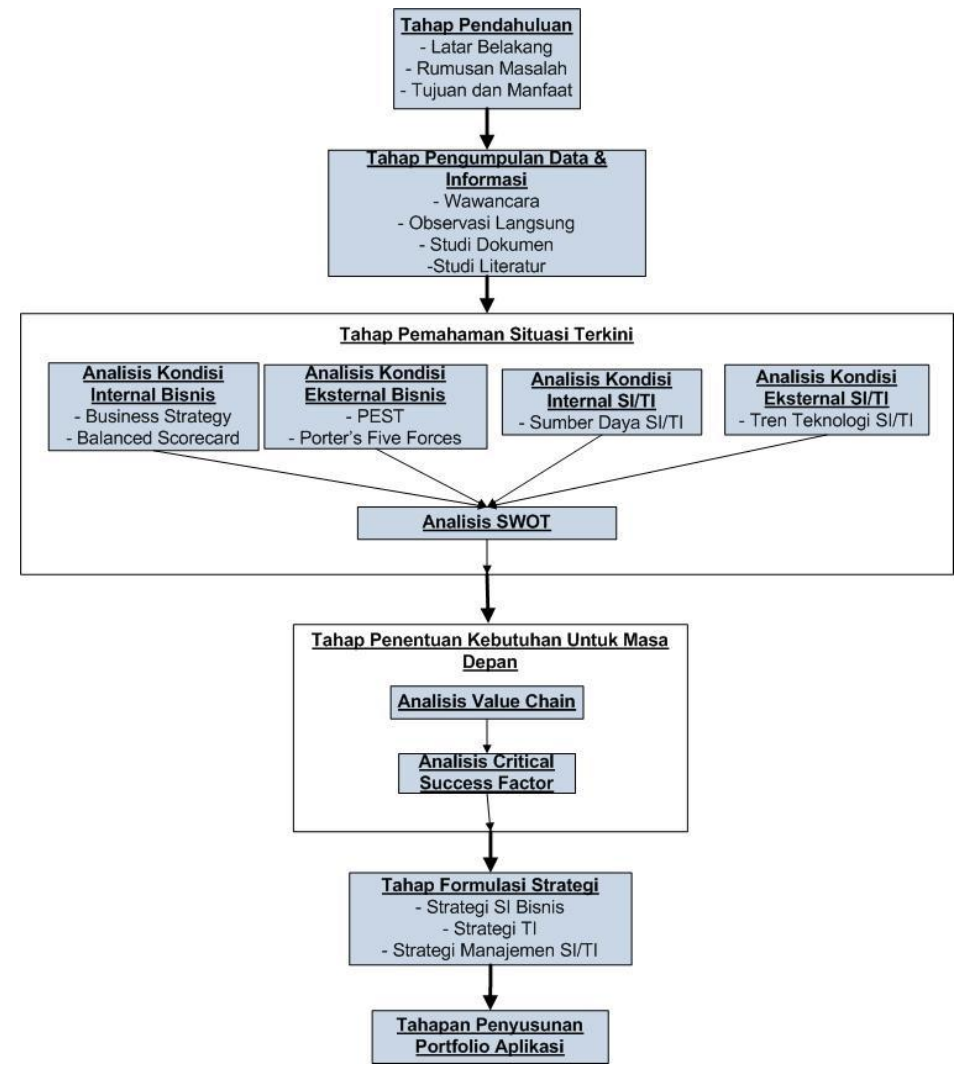

Gambar 1.Tahap - Tahap Penelitian

\section{Tahap Pendahuluan}

Tahap ini merupakan tahap awal penelitian. Dalam tahap ini dilakukan penentuan latar belakang, kemudian merumuskan masalah, serta menetapkan tujuan penelitian dan manfaat yang hendak dicapai.

\section{Tahap Pengumpulan Data dan Informasi}

Tahap ini merupakan tahap untuk mengumpulkan berbagai data dan informasi terkait objek penelitian yaitu Baristand Industri Surabaya. Cara - cara yang akan diambil antara lain dengan wawancara, observasi langsung dan studi atas dokumen - dokumen terkait dan studi literatur.

\section{Tahap Pemahaman Situasi Terkini}

Tahap ini bertujuan untuk memahami kondisi terkini yang sedang dihadapi baik oleh organisasi secara keseluruhan, maupun pada aspek SI/TI. Akan dilakukan analisis lingkungan internal mapun eksternal. Agar lebih jelas, analisis kondisi Baristand Industri Surabaya secara keseluruhan dipisahkan dari analisis kondisi SI/TI.

Lingkungan internal Baristand Industri Surabaya dianalisis dengan analisis Business Strategy dan Balanced Score Card. Lingkungan eksternal yang dihadapi Baristand Industri Surabaya dianalisis dengan analisis PEST dan Porter's Five Forces. Untuk lingkungan internal SI/TI, penelitian ini mempelajari sumber daya apa saja yang dimiliki Baristand Surabaya terkait dengan SI/TI. Untuk analisis kondisi eksternal SI/TI, dilakukan analisis tren teknologi informasi. Kesemua analisis tersebut digunakan untuk menghasilkan gambaran terhadap kontribusi SI/TI terhadap kegiatan bisnis Baristand Industri Surabaya, serta seberapa selaras SI/TI saat ini terhadap strategi bisnis. Dari gambaran tersebut, dicari bagaimana ara menyelaraskan SI/TI dengan strategi bisnis Baristand Industri Surabaya.

\section{Tahap Penentuan Kebutuhan Untuk Masa Depan}

Pada tahap ini, penelitian mempelajari mengenai kondisi SI/TI yang diinginkan untuk masa depan, dan apa saja yang dibutuhkan untuk mencapainya. Dalam tahapan dilakukan analisis value chain, kemudian analisis critical success factor. Hasil dari kedua analisis ini menjadi masukan bagi analisis kesenjangan antara kondisi saat ini dan kondisi yang diinginkan di masa depan.

\section{Tahap Formulasi Strategis}

Dalam tahapan ini, strategi SI/TI akan disusun. Ada tiga jenis strategi yang akan dihasilkan dari tahapan ini yaitu Strategi SI Bisnis, Strategi TI dan Strategi Manajemen SI/TI. Strategi SI Bisnis akan menjadi pedoman untuk menjamin SI agar mendukung pencapaian sasaran bisnis. Strategi TI akan menjadi rekomendasi mengenai infrastruktur / perangkat keras dan pengembangan keahlian SDM agar SI bejalan sesuai harapan. Strategi Manajemen SI/TI akan menjadi rekomendasi mengenai tatakelola SI/TI.

\section{Tahap Penyusunan Portfolio Aplikasi}

Penelitian ini juga diharapkan mampu menghasilkan portfolio aplikasi yang merupakan rekomendasi aplikasi aplikasi apa saja yang perlu diperoleh di masa depan. Portfolio disusun berdasarkan Strategi SI Bisnis dan diperoleh melalui Mcfarlan's Strategic Grid.

\section{HASIL DAN PEMBAHASAN}

Analisis kondisi lingkungan bisnis eksternal Baristand Industri Surabaya memberikan gambaran peluang (Opportunities) dan ancaman (Threats) yang dihadapi. Sedangkan analisis kondisi internal bisnis Baristand Industri Surabaya memberi gambaran keunggulan (Strengths) dan kelemahan (Weaknessess) yang dimiliki. Analisis SWOT 
dilaksanakan untuk mengetahui posisi strategis Baristand Industri Surabaya. Hasilnya tergambar sebagaimana pada gambar 1 berikut :

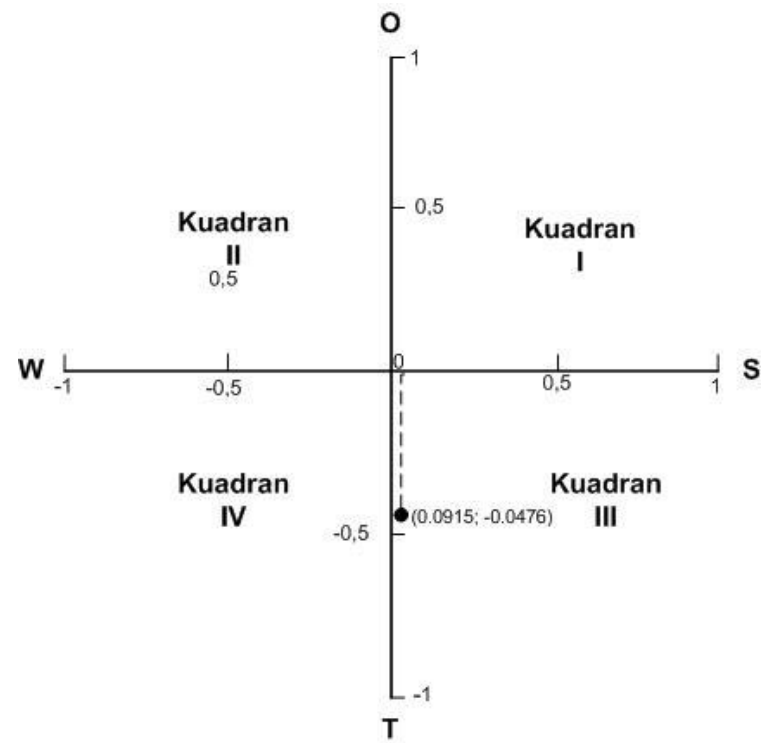

Gambar 2. Letak Baristand Industri Surabaya dalam Kuadran SWOT
Dari gambar kuadran disimpulkan bahwa Baristand Industri Surabaya berada pada Kuadran III atau posisi ST. Baristand Surabaya perlu memanfaatkan dan meningkatkan kekuatan internalnya untuk mengantisipasi berbagai ancaman yang terjadi. Baristand Surabaya juga perlu mengurangi atau menutupi kelemahannya, sebab keunggulan dari kekuatan dibanding kelemahan tidak besar (kurang dari 0,1).

Portfolio aplikasi SI Baristand Industri Surabaya dianalisis sebagai bagian dari analisis kondisi SI/TI yang tengah berjalan. Tiap aplikasi dari portfolio diklasifikasikan sesuai dengan Mcfarlan Strategic Grid, dengan menggunakan metode dari Ward dan Peppard (2002). Hasil klasifikasinya adalah sebagaimana tabel 1 berikut :

\section{TABEL I. KLASIFIKASI PORTFOLIO APLIKASI BARISTAND} INDUSTRI SURABAYA

\begin{tabular}{|l|l|}
\hline Strategic & High Potential \\
\hline $\begin{array}{l}\text { Aplikasi SIP (Sistem Informasi } \\
\text { Pelayanan) }\end{array}$ & $\begin{array}{l}\text { SMS Center } \\
\text { Website Promosi } \\
\end{array}$ \\
\hline Key Operational & Suppoard Kinerja \\
\hline & Aplikasi SNI Corner \\
\hline
\end{tabular}

Kegiatan bisnis di Baristand Industri Surabaya dibagi dalam kegiatan bisnis utama dan pendukung, sesuai model value shop yang diperkenalkan Stabell dan Fjelstad (1998). Model value shop dari Baristand Industri Surabaya adalah sebagai berikut :

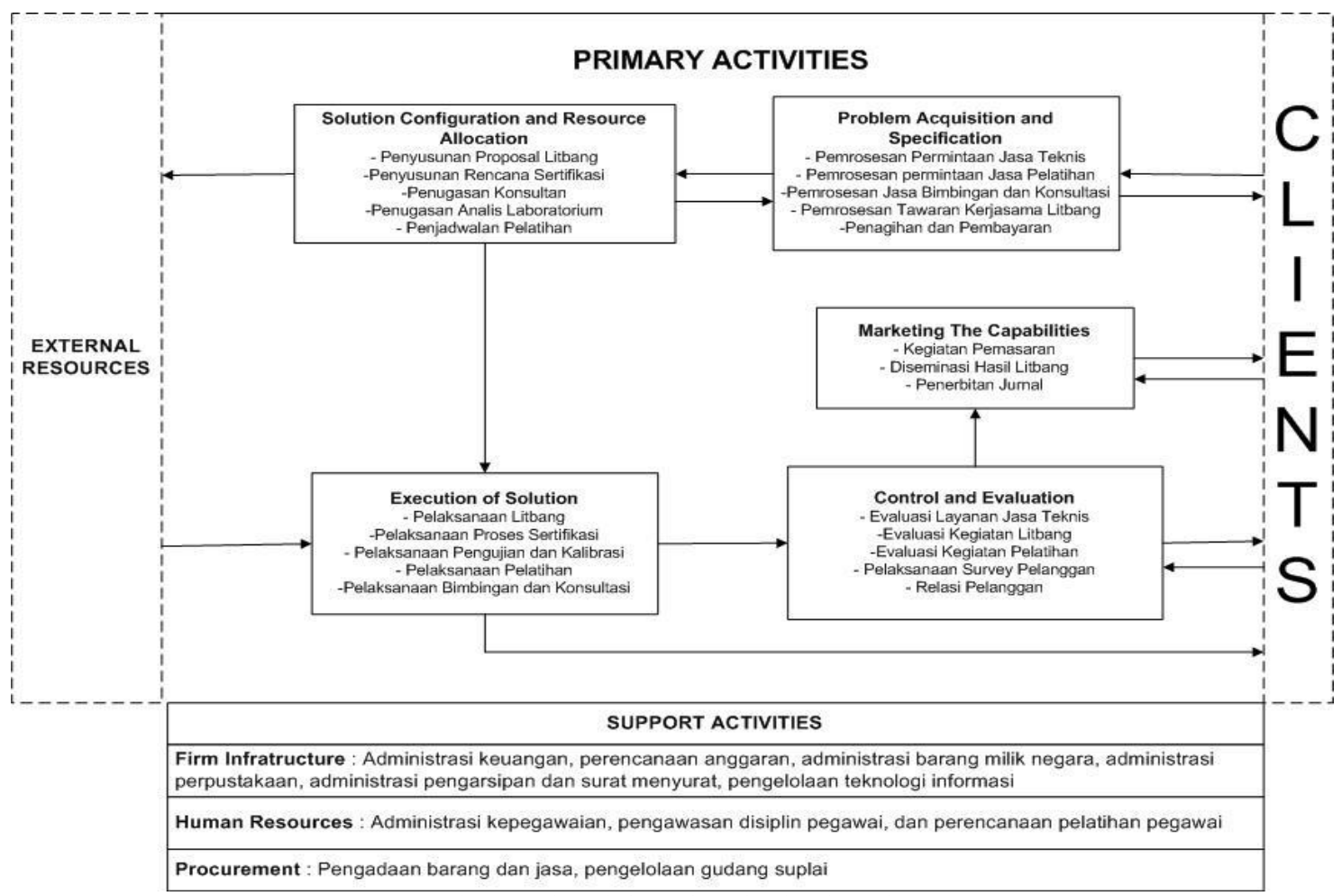

Gambar 3. Value Chain Baristand Industri Surabaya 
Proses identifitikasi Critical Success Factor (CSF) menghasilkan $7 \mathrm{CSF}$ dari Baristand Industri Surabaya sebagaimana pada tabel 2 berikut ini :

TABEL II. CSF BARISTAND INDUSTRI SURABAYA

\begin{tabular}{|c|c|c|}
\hline Kode & Deskripsi & $\begin{array}{c}\text { Kebutuhan Data dan } \\
\text { Informasi }\end{array}$ \\
\hline CSF01 & $\begin{array}{lr}\text { Dengan } & \text { meningkatkan } \\
\text { kualitas dan } & \text { kuantitas } \\
\text { pelatihan } & \end{array}$ & $\begin{array}{llr}\text { - } & \text { Data litbang } & \text { yang } \\
\text { sedang } & \text { dan } & \text { tengah } \\
\text { berjalan } & & \\
& \end{array}$ \\
\hline CSF02 & $\begin{array}{llr}\text { Dengan } & \text { melaksanakan } \\
\text { layanan } & \text { sesuai } & \text { ISO } \\
9001: 2008 & & \end{array}$ & $\begin{array}{ll}- & \text { Sistem informasi } \\
& \text { layanan } \\
\text { - } & \text { Sistem monitoring indek } \\
& \text { kepuasan pelanggan }\end{array}$ \\
\hline CSF03 & $\begin{array}{l}\text { Dengan melaksanakan } \\
\text { akreditasi jurnal }\end{array}$ & $\begin{array}{ll}\text { - } & \text { Sistem penerbitan jurnal } \\
& \text { secara online }\end{array}$ \\
\hline CSF04 & $\begin{array}{l}\text { Dengan melaksanakan } \\
\text { pemasaran hasil litbang, } \\
\text { jurnal, layanan jasa } \\
\text { teknis, pelatihan dan } \\
\text { konsultasi dari Baristand } \\
\text { Industri Surabaya }\end{array}$ & $\begin{array}{ll}\text { - } & \text { Sarana promosi secara } \\
& \text { elektronik } \\
\text { - } & \text { Sarana komunikasi } \\
& \text { dengan dunia industri }\end{array}$ \\
\hline CSF05 & $\begin{array}{lr}\text { Dengan } & \text { mengembangkan } \\
\text { kemampuan } & \text { SDM } \\
\text { Baristand } & \text { Industri } \\
\text { Surabaya } & \end{array}$ & $\begin{array}{l}\text { - Data kepegawaian dan } \\
\text { riwayat pendidikan dan } \\
\text { pelatihan }\end{array}$ \\
\hline CSF06 & $\begin{array}{lr}\text { Dengan } & \text { meningkatkan } \\
\text { sarana } & \text { laboratorium } \\
\text { Baristand } & \text { Industri } \\
\text { Surabaya } & \end{array}$ & $\begin{array}{llr}\text { - } & \text { Data } & \text { sarana, } \\
& \text { perlengkapan dan } \mathrm{BMN} \\
& \text { Baristand } & \text { Industri } \\
& \text { Surabaya } & \\
\text { - } & \text { Sistem } & \text { pengadaan } \\
& \text { secara onlne } & \end{array}$ \\
\hline CSF07 & $\begin{array}{l}\text { Mendirikan dan } \\
\text { menjalankan sistem } \\
\text { pengendalian internal }\end{array}$ & $\begin{array}{ll}\text { - } & \text { Data keuangan } \\
\text { - } & \text { Data capaian strategis }\end{array}$ \\
\hline
\end{tabular}

Semua analisis tersebut menjadi bahan untuk analisis kesenjangan kebutuhan SI/TI. Dari analisis kesenjangan didapat beberapa usulan langkah - langkah strategis SI/TI. Usulan - usulan langkah strategis SI/TI kemudian diserahkan pada Seksi PJT Baristand Industri Surabaya untuk direspon. Hasil respon sebagai berikut :
TABEL III. USULAN LANGKAH STRATEGI SI/TI DAN RESPONNYA

\begin{tabular}{|c|c|c|}
\hline No & Usulan Langkah Strategis & Respon Dari Seksi PJT \\
\hline 01 & $\begin{array}{lrr}\text { Membuat } & \text { suatu } & \text { sistem baru } \\
\text { yaitu Sistem } & \text { Informasi } \\
\text { Kegiatan Litbang } & \text { Baristand } \\
\text { Industri Surabaya } & \end{array}$ & Disetujui \\
\hline $\mathbf{0 2}$ & Memperbarui SIP & $\begin{array}{l}\text { Disetujui, tetapi beberapa } \\
\text { fitur ada yang pembaruannya } \\
\text { tidak diprioritaskan }\end{array}$ \\
\hline $\mathbf{0 3}$ & $\begin{array}{l}\text { Memperbarui } \quad \text { Dashboard } \\
\text { Kinerja }\end{array}$ & Disetujui \\
\hline 04 & Memperbarui SMS Center & $\begin{array}{l}\text { Diterima tetapi tidak } \\
\text { diprioritaskan }\end{array}$ \\
\hline 05 & Memperbarui SNI Corner & Ditolak \\
\hline 06 & $\begin{array}{l}\text { Membuat suatu sistem baru } \\
\text { yaitu Sistem Survey Kepuasan } \\
\text { Pelanggan }\end{array}$ & $\begin{array}{l}\text { Diterima tetapi tidak } \\
\text { diprioritaskan }\end{array}$ \\
\hline 07 & $\begin{array}{l}\text { Membuat sistem baru yaitu } \\
\text { Sistem Informasi Arsip dan } \\
\text { Dokumen }\end{array}$ & $\begin{array}{l}\text { Disesuaikan sebab ada } \\
\text { rencana serupa dari kantor } \\
\text { pusat kemenperin }\end{array}$ \\
\hline 08 & $\begin{array}{l}\text { Mengganti Website Promosi } \\
\text { Baristand Industri Surabaya } \\
\text { dengan website yang lebih baru }\end{array}$ & Disetujui \\
\hline 10 & $\begin{array}{l}\text { Memperbarui infrastruktur } \\
\text { perangkat keras } \quad \text { Baristand } \\
\text { Indsustri Surabaya. }\end{array}$ & Disetujui \\
\hline 11 & $\begin{array}{l}\text { Membuat } \quad \text { barudokumen } \\
\text { rencana strategis SI/TI dan } \\
\text { master plan SI }\end{array}$ & Disetujui \\
\hline 12 & $\begin{array}{l}\text { Memperbarui sistem } \\
\text { pengarsipan dokumen dan } \\
\text { catatan operasional pengelolaan } \\
\text { SI/TI }\end{array}$ & $\begin{array}{l}\text { Disesuaikan dengan rencana } \\
\text { pusat }\end{array}$ \\
\hline 13 & $\begin{array}{lll}\text { Memperbarui koordinasi tim } \\
\text { pengelola TI } & & \\
\end{array}$ & $\begin{array}{l}\text { Diterima tetapi tidak } \\
\text { diprioritaskan }\end{array}$ \\
\hline 14 & \multicolumn{2}{|c|}{$\begin{array}{l}\text { Masukan Tambahan dari Baristand : Membuat baru sistem } \\
\text { informasi publik }\end{array}$} \\
\hline
\end{tabular}

Dari semua usulan hanya satu yang ditolak sepenuhnya. Usulan lainnya diterima sepenuhnya, disesuaikan atau walau diterima tetapi tidak diprioritaskan.Kondisi di Baristand yang menghadapi berbagai keterbatasan menyebabkan perlunya prioritisasi. Proses prioritisasi memungkinkan penyusunan strategi SI/TI yang dapat segera menjembatani kebutuhan 
SI/TI dalam batasan yang ada, dan tetap membuka kemungkinan untuk langkah yang di luar batasan untuk diimplementasikan bila kondisi lebih baik atau memungkinkan.

Adanya langkah tambahan yang diusulkan merupakan suatu kegagalan dalam identifikasi kebutuhan SI/TI. Kegagalan ini disebabkan adanya tuntuan baru dari pemerintah pusat dan masyarakat yang muncul setelah Dokumen Renstra disetujui dan digunakan. Munculnya tuntutan baru dari pemerintah dan masyarakat merupakan suatu perkembangan baru yang tidak terlingkupi dalam Renstra.

Diharapkan dalam dua tahun setelah Baristand Industri Surabaya memulai untuk mengimplementasikan langkah langkah utama strategi SI/TI, Baristand akan memiliki Dokumen Renstra SI/TI dan Master Plan SI serta portfolio aplikasi dengan posisis strategis sebagaimana tabel 4 berikut ini :

TABEL IV. PORTFOLIO YANG INGIN DICAPAI DALAM 2 TAHUN

\begin{tabular}{l|l}
\hline \multicolumn{1}{c|}{ Strategic } & \multicolumn{1}{c}{ High Potential } \\
\hline $\begin{array}{l}\text { Aplikasi SIP (Sistem } \\
\text { Informasi Pelayanan) }\end{array}$ & SMS Center \\
\hline Website Promosi & $\begin{array}{l}\text { Sistem Informasi } \\
\text { Publik }\end{array}$ \\
\hline Dashboard Kinerja & \\
\hline Sistem Informasi Litbang & \\
\hline Key Operational & Support \\
\hline & Aplikasi SNI Corner \\
\hline
\end{tabular}

\section{KESIMPULAN}

Dari penelitian yang telah dilaksanakan, ada dua kesimpulan yang ditarik. Pertama, metode Ward dan Peppard secara umum mampu mengidentifikasi kebutuhan SI/TI dan menjadi basis rencana strategis SI/TI di Baristand Industri Surabaya, kecuali bila ada tuntutan baru yang tidak terantisipasi, dan harus dilaksanakan proses prioritisasi terhadap usulan strategis SI/TI. Kedua, metode Ward dan Peppard yang dikombinasikan dengan langkah prioritisasi, mampu memberikan usulan - usulan langkah strategi SI/TI, yang menghasilkan portfolio SI dan kondisi SI/TI yang secara keseluruhan mampu mendukung pencapaian sasaran strategis Baristand Industi Surabaya. Diperlukan analisis lebih lanjut mengenai efektivitas implementasinya dalam mendukung pencapaian sasaran strategis, sehingga akuntabilitas pengelolaan SI/TI meningkat.

Bagi penelitian di masa depan terhadap lembagai pelayanan publik dengan kondisi yang serupa dengan penelitian ini, terdapat beberapa saran untuk penelitian di masa depan. Pada penelitian ini terdapat tuntutan baru dari pemerintah dan masyarakat yang tidak terantisipasi dalam renstra. Diperlukan penelitian apakah lembaga layanan publik dengan kondisi serupa juga memiliki permasalahan serupa dan apakah dapat dikembangkan strategi untuk menghadapinya. Berkaitan dengan prioritisasi langkah strategi dibagi dalam tiga skala (diterima, ditunda, dan ditolak) dan dinilai dengan kriteria batasan biaya dan waktu pelaksanaan, maka perlu penelitian lebih lanjut apakah skala dan kriteria prioritas pada lembaga layanan publik lainnya dengan kondisi yang serupa juga sama. Dan bila ada perbedaan, apakah ada cara untuk menstandarkan langkah prioritiasisi. Selain itu, diperlukan juga analisis mengenai efektivitas impelementasi strategi SI/TI yang telah selaras dengan dokumen Rentra Baristand Industri Surabaya dalam mencapai sasaran - sasaran strategisnya dan memperbaiki posisi strategisnya. Analisis sebaiknya memperhitungkan juga biaya dan sumber daya yang dikeluarkan untuk impelementasi, sehingga meningkatkan akuntabilitas pengelolaan SI/TI.

\section{UCAPAN TERIMA KASIH}

Ucapan terima kasih dihaturkan pada Ibu Ir. Siti Rohmah Siregar, MM selaku kepala Baristand Industri Surabaya dan Ibu Fatimah, SE.MM selaku kepala seksi Pengembangan Jasa Teknis, Tim pengelola teknologi informasi Baristand Industri Surabaya, terutama Saudari Aneke Rintiasti, S.Kom, MT selaku ketua tim, para staf Baristand Industri Surabaya, dan para staf program studi MMT - ITS, serta semua pihak yang telah membantu dan tidak dapat disebutkan satu persatu.

\section{DAFTAR PUSTAKA}

[1] Baristand Industri Surabaya. (2016). Laporan Kinerja Baristand Industri Surabaya 2015. Baristand Industri Surabaya

[2] Baristand Industri Surabaya. (2014). Rencana Strategis Baristand Industri Surabaya 2015 -2019. Baristand Industri Surabaya

[3] Chan Yolande E. , Sabheral, Rajiv., \& Thatcher, Jason Bennet. (2006). Antecedents and Outcomes of Strategic IS Alignment. IEEE Transactions On Engineering Managemen, Vol. 53, No. 1, Hal. 27 - 47

[4] Chen, Daniel Q. , Mocker, Martin., Preston, David S., \& Teubner, Alexander. (2010). Information System Strategy: Reconceptualization, Measurement and Implication. MIS Quarterly 34 (2), 233 - 259

[5] David, Fred R. (2013). Strategic Management Concepts and Cases Fourteenth Edition Global Edition. Essex, England: Pearson Education Limited.

[6] Fikriyah, Laily. \& Samopa, Febriliyan. (2014). Perencanaan Strategis Sistem Informasi/Teknologi Informasi di PT. Perkebunan Nusantara XI. Program Studi MMT-ITS.

[7] Garg, A.K. , Joubert R.J.O., \& Pellisier, R. (2005). Information Systems Environmental Alignment and Business Performance: A Case Study. South Africa Journal of Business Management, Vol 36, No. 4, Hal. 33 53 .

[8] Kaplan, Robert S. (1999). Using The Balanced Scorecard for Public Sector Organization. (Versi Cetak Ulang). Harvard Business Review

[9] Kaplan, Robert S. \& Norton, David P. (2007). Using The Balanced Scorecard as a Strategic Management System. (Versi Cetak Ulang). Harvard Business Review 
[10] Kearns, Grover S. \& Sabherwhal, Rajiv. (2007). Strategic Alignment Between Business and Information Technology. Journal of Management Information Systems, Vol 23, No. 3, Hal. 129 - 162

[11] McFarlan, F. Warren. (1984). Information Technology Changes The Way You Compete. Harvard Business Review

[12] Peraturan Menteri Pendayagunaan Aparatur Negara dan Reformasi Birokrasi No. 16 Tahun 2015 Tentang Road Map Reformasi Birokrasi Internal Tahun 2015 - 2019.

[13] Peraturan Menteri Perindustrian No. 49/M-IND/PER/6/20006 Tentang Organisasi dan Tata Kerja Balai Riset dan Standardisasi Industri

[14] Porter, Michael E. (2008). The Five Competitive Forces That Shape Strategy. Harvard Business Review

[15] Rockart, John F. (1979). Chief Executive Define Their Own Data Needs. Harvard Business Review
[16] Stabell, Charles B. \& Fjeldstad, Øystein D.(1998). Configuring Value For Competitive Advantage: On Chains, Shops And Networks. Strategic Management Journal, Vol. 19, Hal 413 - 417

[17] Tanriverdi, Hüseyin ., Rai, Arun., \& Venkatraman, N.(2010). Reframing the Dominant Quests of Information Systems Strategy Research for Complex Adaptive Business Systems. Information Systems Research, Vol. 21, No. 4, Hal 822 - 834

[18] Thiernan, Chris \& Peppard, Joe (2004). Information Technology: Of Value or Vulture? European Management Journal, Vol. 22, No. 6, Hal $609-623$

[19] Ward, John \& Peppard, Joe. (2002). Strategic Planning For Information System. Cranfield, Berthfordshie, United Kingdom: John Wiley \& Sons, LTD. 